\title{
Asthma, Bones \& Corticosteroids: Are inhaled corticosteroids associated with fractures in children with asthma?
}

Saskia E Zieck ${ }^{1,2}$ (BPharm), Johnson George ${ }^{2}$ (MPharm, PhD), Brooke A Blakeley ${ }^{1,2}$ (BPharm Sci), Liam Welsh (BAppSci, PhD) ${ }^{1,3}$, Simon James ${ }^{4}$ (BSci(Mathematics)(Hons), PhD), Sarath Ranganathan $^{1,3,5}$ (MBBS, PhD), Peter Simm ${ }^{1,3,5}$ (MBBS, MD), Angelina Lim ${ }^{1,2}$ (BPharm(Hons), PhD)

1. Murdoch Childrens Research Institute, Royal Children's Hospital, 50 Flemington Rd, Parkville 3052, Victoria, Australia

2. Centre for Medicine Use and Safety, Faculty of Pharmacy and Pharmaceutical Sciences, Monash University, Parkville 3052, Victoria, Australia

3. Royal Children's Hospital, 50 Flemington Rd, Parkville 3052, Victoria, Australia

4. School of Information Technology, Deakin University

5. Department of Paediatrics, University of Melbourne, 50 Flemington Rd, Parkville 3052, Victoria, Australia

Type of article: original article

Corresponding author and person whom reprint requests should be addressed to:

Dr Angelina Lim

Centre for Medicine Use and Safety,

Faculty of Pharmacy and Pharmaceutical Sciences,

Monash University, Parkville 3052, Victoria, Australia

Email: angelina.lim@monash.edu.au

Phone: 0399039014

Fax: 0399039629

Disclosure statement: All authors declare no conflict of interest. Dr Johnson George has financial support for unrelated research from Boehringer Ingelheim and Pfizer.

This is the author manuscript accepted for publication and has undergone full peer review but has not been through the copyediting, typesetting, pagination and proofreading process, which may lead to differences between this version and the Version of Record. Please cite this article as doi: $10.1111 /$ jpc.13554

This article is protected by copyright. All rights reserved. 


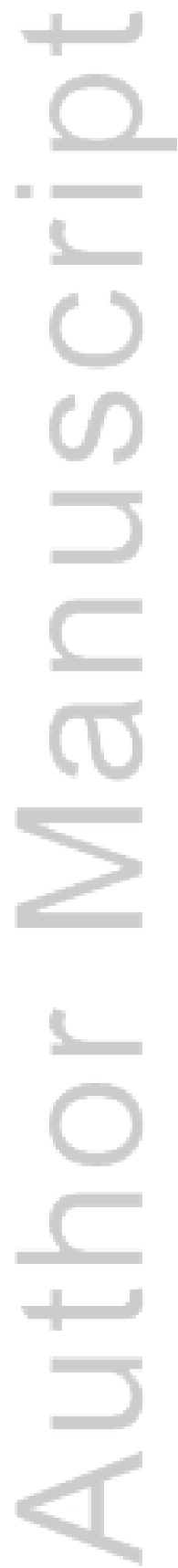

This article is protected by copyright. All rights reserved. 


\begin{abstract}
:
Aim: The prevalence of asthma worldwide among older children varies between 10 and $20 \%$. One of the most effective therapies to treat asthma and prevent exacerbations is inhaled corticosteroids (ICS). Systemic corticosteroids are known to decrease bone mineral density (BMD) and increase the risk of fractures among children, but little is known about the effect of ICSs on fracture risk in children with asthma. The aim of this study was to investigate the fracture rates in children with asthma using ICSs.
\end{abstract}

Methods: A survey on fracture history and risk, bone health and asthma was administered by a researcher to children aged 6-18 years attending a tertiary care children's hospital in Melbourne, Australia over a six month period. Fracture risks were compared in children on low or high dose ICS with those not on any ICS and non-asthmatics. Results: 216 healthy control participants were compared with 211 children with asthma - 22\% $(n=46)$ on low dose ICS therapy, $44 \%(n=94)$ on high dose ICS, and $34 \%(n=71)$ not on any ICS. There was no difference in the incidence of fractures between children with asthma $(24.6 \% \mathrm{n}=53)$ and healthy controls $(24 \% \mathrm{n}=51)\left(C C_{2}=0.132 ; \mathrm{p}=0.717\right)$. There were no differences in fracture incidence in the subgroups of children with asthma $(p=0.695)$. Conclusion: ICS use was not associated with fracture risk in children with asthma.

Keywords: Endocrinology, Respiratory, Pharmacology

\title{
What is already known on this topic?
}

- Inhaled corticosteroids are the mainstay of asthma therapy in children with asthma

- It is known that low dose ICS use does not have significant effects on bone mineral density

- Effect of high doses of inhaled corticosteroids (ICS) on fracture risk in children with asthma has not been studied adequately

\section{What this paper adds?}

- No significant differences in fracture risk among high and low dose ICS users

- No increased risk of fractures among children with asthma compared to non-asthmatic controls

- Predefined risk factors did also not seem to have an effect on the risk of fractures in children with asthma compared with healthy controls. Large cohort studies with long follow-ups in 
which the time relation between ICS and fracture occurrence is known are necessary to determine the longer-term effects of ICS on bone health and safety in children with asthma.

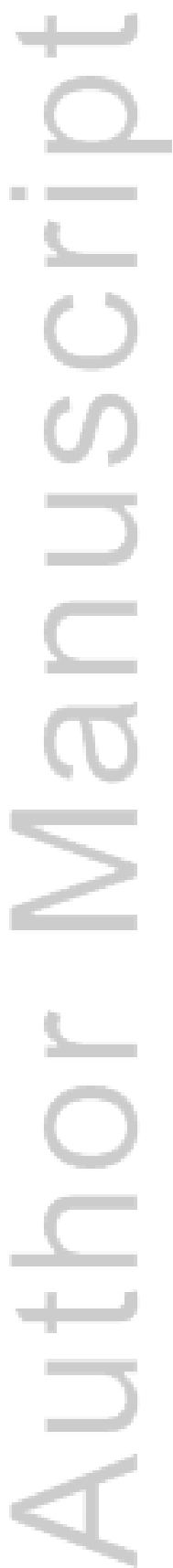

This article is protected by copyright. All rights reserved. 


\section{Main text:}

\section{Introduction:}

The prevalence of asthma worldwide among children, between 6 and 18 years, varies between 10 and $20 \%$. ${ }^{1}$ One of the most effective therapies to treat asthma and prevent exacerbations is inhaled corticosteroids (ICS). ${ }^{2-4}$ Systemic corticosteroids are known to decrease bone mineral density (BMD) and therefore are associated with a higher risk of fractures among children. ${ }^{5-6}$ Although ICSs are generally considered safe, their effects on fracture risk in children with asthma still remains unclear. ${ }^{7-8}$ Fractures occur commonly in children; Cooper et al. ${ }^{9}$ has reported a fracture risk of $33 \%$ among children 0 to 17 years of age.

Recent studies indicate that high dose ICSs and oral corticosteroids are associated with decreased BMD, and a dose-dependent increased risk of fractures in adults. ${ }^{10-11}$ The effect of high doses of ICS on fracture risk in children with asthma still remains unclear. ${ }^{12-19}$ There is currently no established protocol or guidelines on how to monitor bone health in children with asthma and limited BMD data in the paediatric asthma population. Uncertainty regarding safety of ICS and fracture risk can potentially translate to poor prescriber adherence to treatment guidelines, poor patient adherence to ICS therapy and poor asthma control. The primary aim of this study was to investigate the association between fracture risk and ICS use (high and low doses) in children. Secondary aims were to explore the effects of age, pubertal status, calcium intake and body mass index (BMI) on fracture risk.

\section{Materials and Methods:}

\section{Study design and setting:}

A questionnaire study was performed to be able to perform a retrospective follow up study to evaluate the association between ICS use and fracture risk. The study was conducted between September 2015 and January 2016 at The Royal Children's Hospital (RCH) in Melbourne, Australia. The RCH is the largest paediatric hospital in Victoria and one of the biggest in Australia, with more than 240,000 specialist clinic appointments and 36,000 overnight stays annually.

\section{Participant identification and recruitment:}

Eligible patients with asthma were recruited from the respiratory and allergy clinics, and the emergency department of the RCH. Potential participants were also flagged to the researchers during 
department meetings, lung function testing and referred by respiratory and general medicine clinicians. Control participants (with no diagnosis of asthma) were recruited through the dental clinics of $\mathrm{RCH}$ while waiting for their appointment. A questionnaire and consent form were handed to eligible participants or their parents/guardians. All study participants signed the informed consent form prior to completing the questionnaire. Children under the age of 14 years were required to have parental/guardian consent.

\section{Inclusion criteria}

Children with asthma aged between 6 and 18 years with a clinical diagnosis of asthma were included. Within this group, three sub-groups were formed: 1) children with asthma and using doses of ICSs

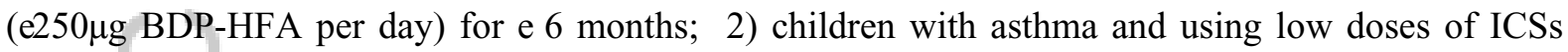
$(<250 \mu$ g BDP-HFA per day) for e 6 months; and 3) children with asthma who were not taking any ICSs These cut-off doses are in line with the National Asthma Guidelines for Paediatric Asthma ${ }^{3}$, and BDP-HFA equivalent dosing, as it is widely used, was chosen for ease of conversion.

Children aged between 6 and 18 years, who neither had a clinical diagnosis of asthma nor a history of ICS use were also included and formed the non-asthmatic control group.

\section{Exclusion criteria}

Children were excluded if they had a history of previous or current use of bisphosphonates or other medication with a known clinical effect on the skeletal bone mineral density (e.g. anti-epileptic medication), or if they had a known primary bone disorder documented in the medical records (e.g. osteogenesis imperfecta). Furthermore, patients were excluded if they could not speak or write English, to prevent misinterpretation of the questionnaire.

\section{Data collection:}

The questionnaire consisted of three parts: a bone health and injury questionnaire, an asthma and corticosteroids questionnaire and the Asthma Control Questionnaire (ACQ). ${ }^{20}$ The bone health and injury questionnaire was used in a previous bone health project investigating fracture risk in children with epilepsy. ${ }^{21}$ The asthma and corticosteroids questionnaire was developed by the investigatory team and was piloted in children 6 years and over $(n=10)$. The questions on the use of ICS were directed at current exposure (the use of ICS during the period the questionnaire was filled up). The 
questionnaires were completed by the parent/guardian on behalf of children under 12 years of age except for the ACQ which was completed by the child as recommended. ${ }^{20}$ Children older than 12 years were eligible to complete the written questionnaire themselves but under parental supervision to reduce recall bias/missing data. Children with asthma underwent spirometry voluntarily to provide forced expiratory volume in one second $\left(\mathrm{FEV}_{1}\right)$, which allowed completion of the 7-item ACQ. Where spirometry could not be performed on the day, the recent lung function test result (within four weeks) was sourced from Medical records. Only the ACQ-6 score (i.e. without lung function data) was used if where there was no $\mathrm{FEV}_{1}$ score. All children with asthma were compared using the ACQ-6 score, then ACQ-7 comparisons were made only when the data were available.

\section{Primary outcome:}

The primary outcome was the incidence of self-reported fractures in their lifetime (grouped into forearm/wrist, upper leg, lower leg, hip, ankle, toe/foot, upper arm, other or multiple). Information regarding age at the time of the incident, cause of fracture and treatment was also captured.

The incidence of fractures in the two groups were compared after adjusting for age, body mass index (BMI), pubertal status (based on age groups 6-9, 10-14 and 15-18 years old), exposure to household smoking, history of bone health medication, calcium intake, family history of osteoporosis and weekly physical activity levels.

\section{Ethics approval}

This project was approved by The Royal Children's Hospital Human Research Ethics Committee; HREC \#35167 and The Monash University Human Research Ethics Committee CF15/33912015001446.

\section{Statistical analysis:}

All data were analysed using the Statistical Package for Social Sciences (SPSS), version 22.0 (IBM, Somers, NY, USA, 2010). A Pearson Chi-square was used to test the difference in the incidence of fractures between children with asthma and healthy controls. A Mann Whitney U test was used to estimate group differences in fracture risks within the different groups of children with asthma. Binary logistic regression was used to investigate the effects of confounding factors on the incidence of fractures in asthmatic children. The significance level was fixed at $p<0.05$. This form of analysis builds a binary prediction model (analogous to a linear regression model) where the significance of the regression coefficient can be associated with a significant influence on the model's accuracy. 


\section{Results:}

Out of 582 eligible patients with asthma identified through medical records, 453 were approached during their clinic appointments (Figure 1). A total of 220 patients with asthma completed the questionnaire (participation rate of 49\%). Out of the 311 randomly selected controls who were approached by convenience sampling, 255 participated (participation rate of $82 \%$ ). After six months of recruitment, the final numbers of participants (Table 1) after applying the exclusion/inclusion criteria were: 211 children with asthma (62\% males and mean [SD] age 11.12[3.3]) and 216 controls (46\% males and mean [SD] age 11.1[3.4]). No significant difference in age, BMI classification and ethnicity were found between groups; however, there were significantly more males among the children with asthma $61,6 \%$ vs $46.3 \%$ ( $\mathrm{p}=0.002)$.

Figure 1. Overview of participant recruitment strategy

Among the 211 children with asthma, 46 (22\%) were using a low dose ICS, 94 (44\%) a high dose ICS and $71(34 \%)$ had no history of ICS use at the time of the interview. There was a significant difference between the groups regarding control of symptoms since diagnosis (Table 2); children with low dose ICS had the highest percentage of improvement of symptoms $(\mathrm{p}=0.029)$. There was also a significant difference in the number of self- reported asthma attacks since diagnosis $(p=0.007)$, and history of hospitalization/emergency room visits $(p=0.005)$ where ICS users had the higher percentages compared with no ICS users. An asthma action plan was possessed by $91 \%$ of the high dose ICS users compared with $89 \%$ of low dose ICS users and $70 \%$ of no ICS users $(p=0.001)$. Selfreported adherence between the high and low ICS groups showed a significant difference $(p=0.032)$, low dose ICS users claimed that they always remember to take their asthma medication (59\%); however, among non-users and high dose ICS users the percentages were all above 50\%. Although physical activity levels between ICS users and asthmatic non-ICS users differed significantly $(p=0.028)$ they did not significantly differ between the different ICS groups $(p=0.102)$.

A total of 104 individuals of the 427 participants (children with asthma and healthy controls) sustained one or more self-reported fractures, giving a fracture incidence of $24.4 \%$ in the population (Table 3). The incidence of fractures within the different groups were $24 \%$ in controls, $21 \%$ in asthmatic non-ICS users, $24 \%$ in low dose ICS users and 29\% in high dose ICS users. When comparing the fracture incidences between the control group and the different subgroups of children with asthma, there were no significant differences $(\mathrm{p}=0.695)$. Most fractures $(44 \%)$ occurred at mid 
pubertal age (10-14 years old) with a median of 11.1 years among both groups. There was no difference in the incidence of fractures between the index group $(24,6 \% \mathrm{n}=53)$ and controls $(24 \%$ $\mathrm{n}=51)(C ̧ 2=0.132 \mathrm{p}=0.717)$ nor within the index group $(\mathrm{p}=0.695)$. In a binary logistic regression model adjusting for potential confounders including age, pubertal status, BMI, exposure to household smoking, history of bone health supplement use, dietary calcium intake, family history of osteoporosis and activity levels, there was no significant difference in the incidence of fractures between the ICS groups $(\mathrm{p}=0.398)$.

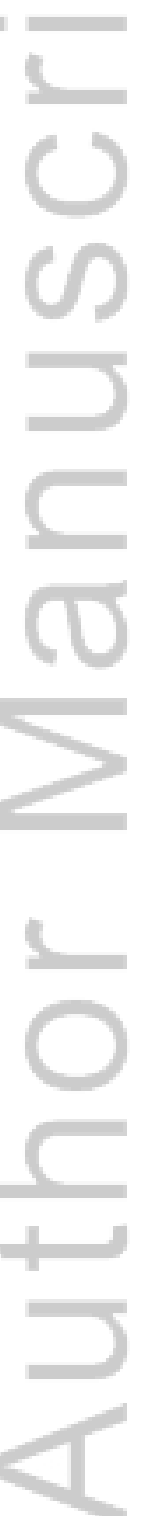




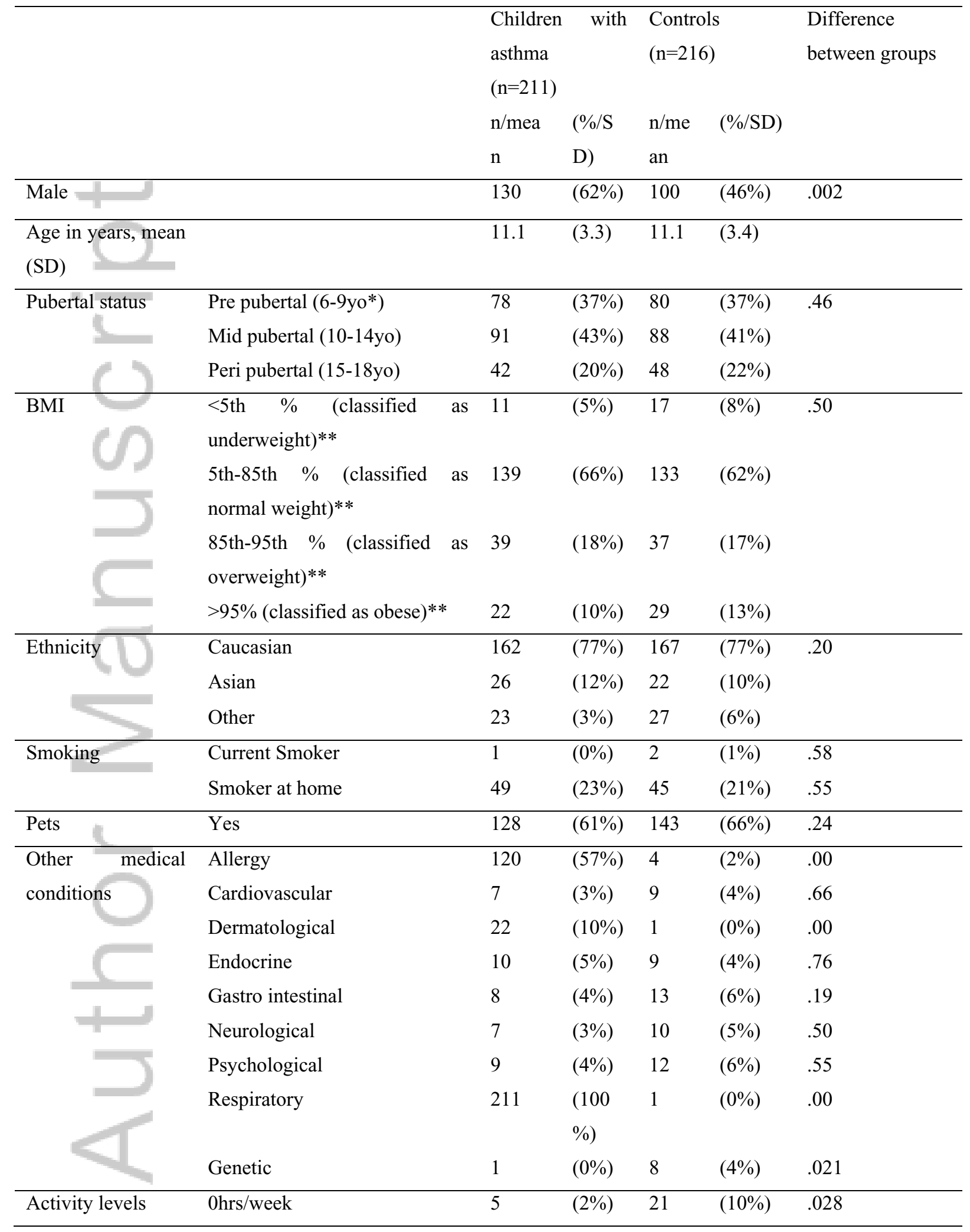




\begin{tabular}{llllll}
\hline $1-3 \mathrm{hrs} /$ week & 54 & $(26 \%)$ & 59 & $(27 \%)$ \\
4-6hrs/week & 60 & $(28 \%)$ & 54 & $(25 \%)$ \\
$5-9 \mathrm{hrs} /$ week & 43 & $(20 \%)$ & 38 & $(18 \%)$ \\
$>10 \mathrm{hrs} /$ week & 49 & $(23 \%)$ & 44 & $(20 \%)$ \\
\hline
\end{tabular}

*yo = years old

** According to The National Center for Health Statistics in collaboration with the National Center for Chronic Disease Prevention and Health Promotion. [Internet] Body mass index-for-age percentiles. 2000, cited; Available from: http://www.cdc.gov/growthcharts

Table 2: Demographics of the study participants with asthma at baseline

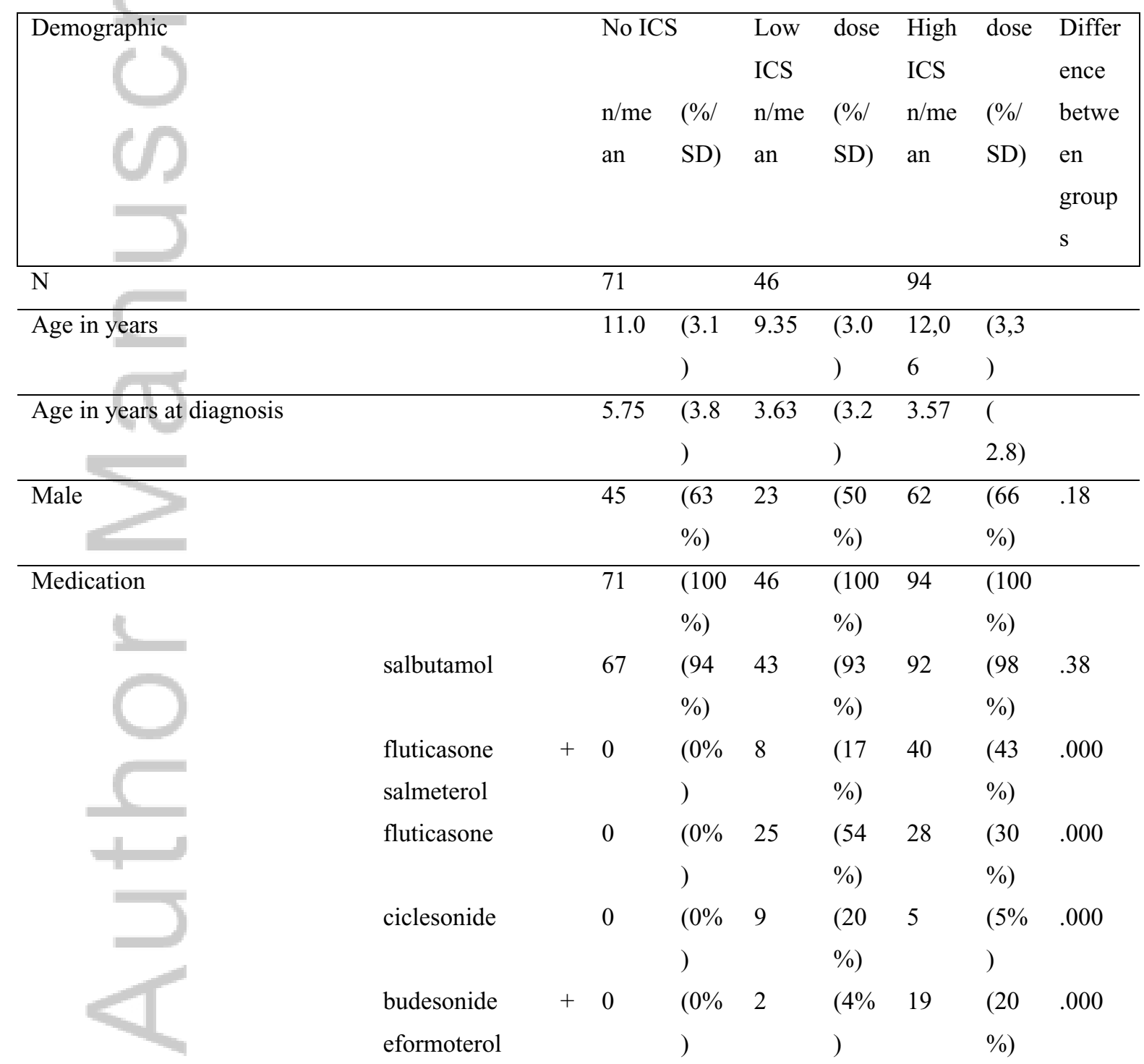




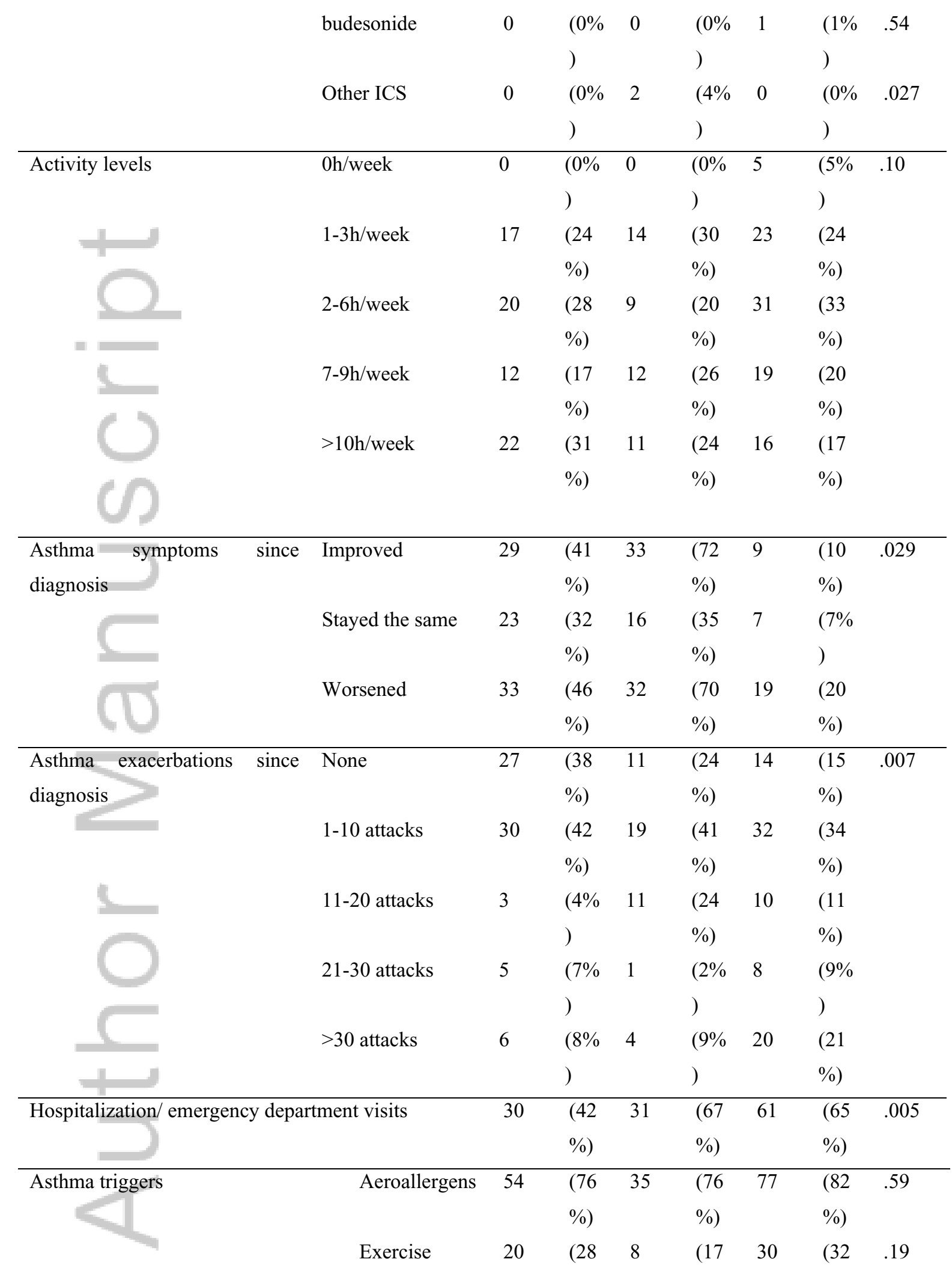




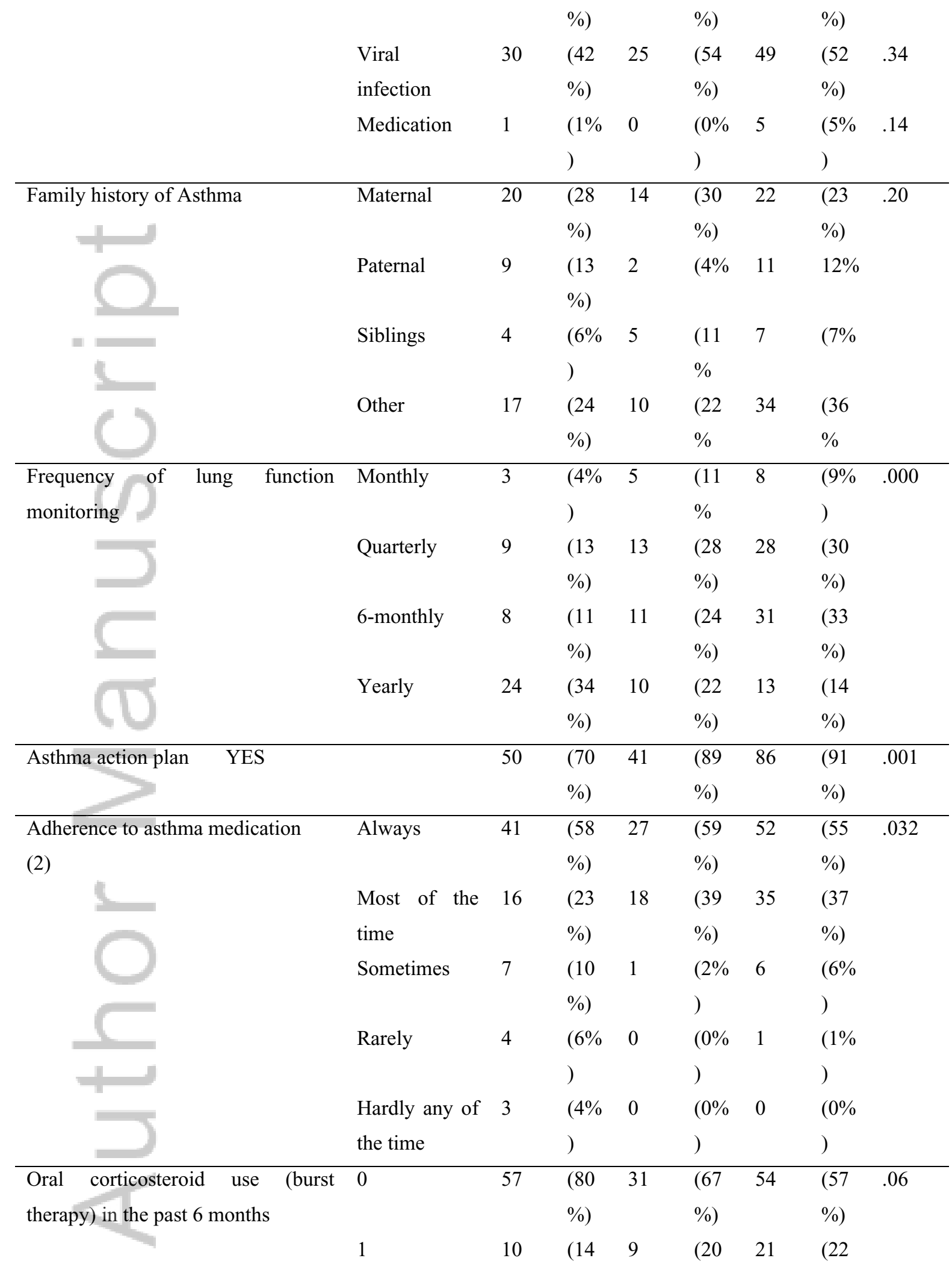




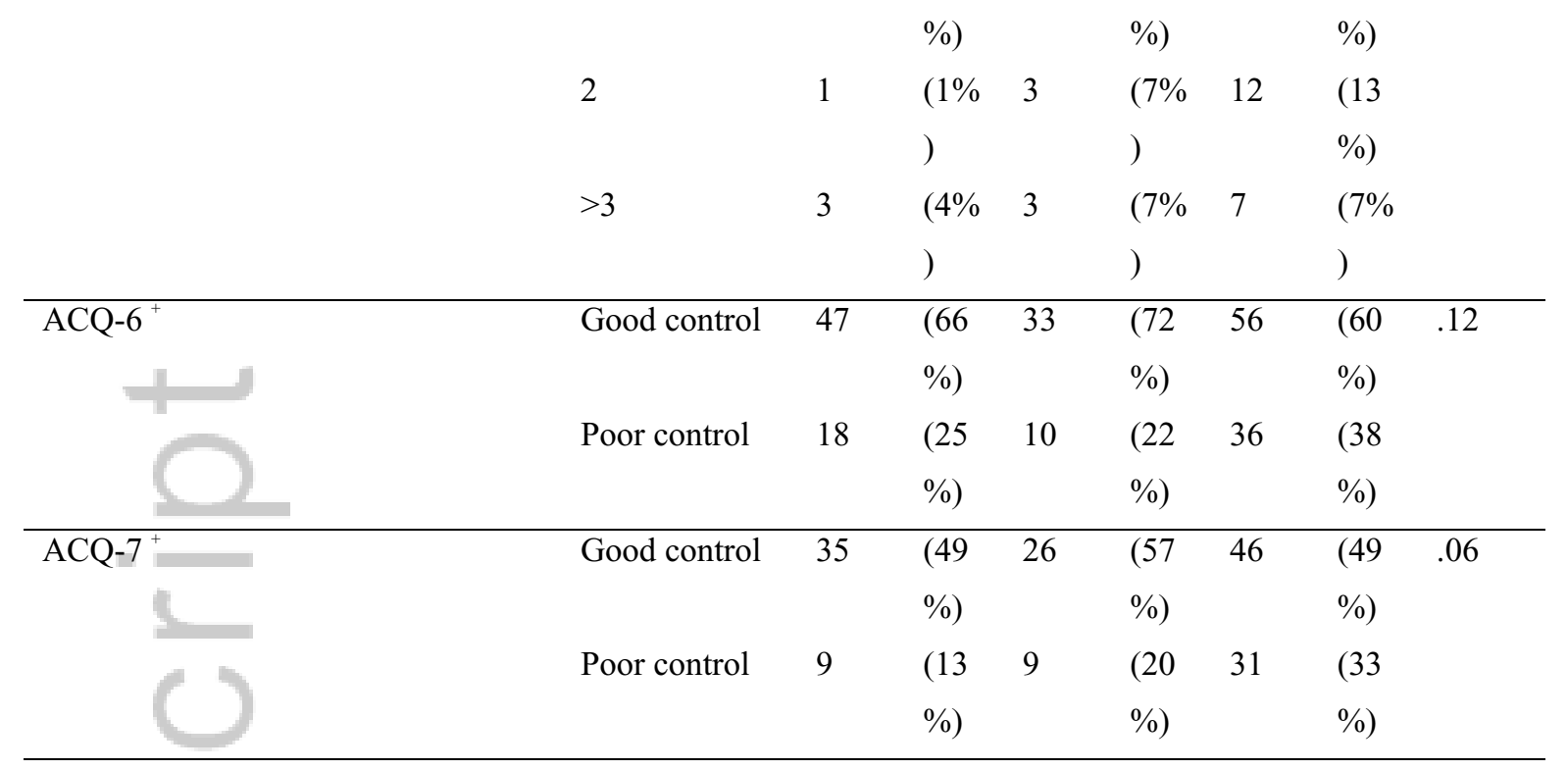

+ ACQ is Asthma Control Questionnaire ${ }^{20}$

This article is protected by copyright. All rights reserved. 


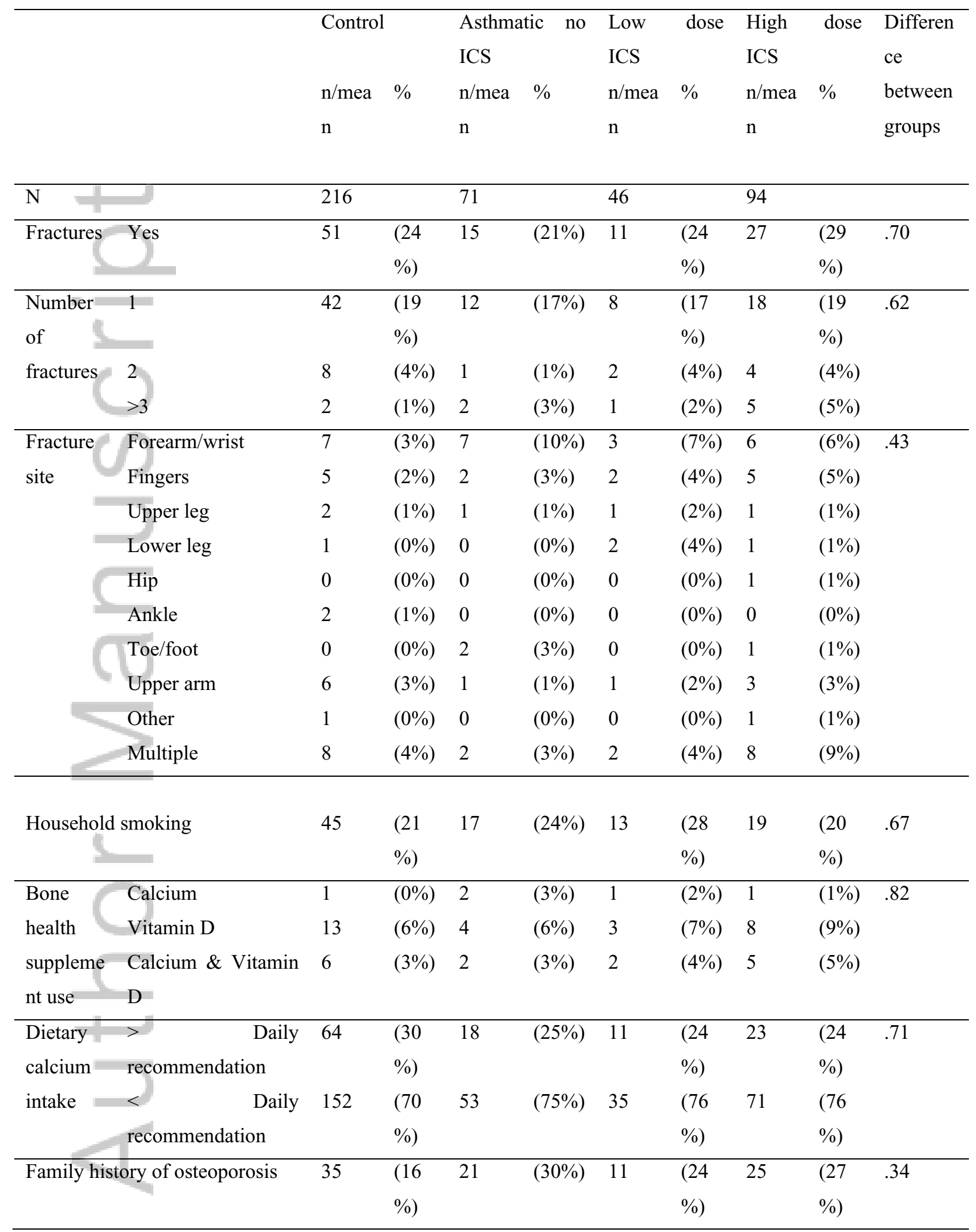




\begin{tabular}{|c|c|c|c|c|c|c|c|c|c|}
\hline Physical & $0 \mathrm{~h} /$ week & 21 & $(10$ & 0 & $(0 \%)$ & 0 & $(0 \%)$ & 5 & $\begin{array}{ll}5 \%) & .05\end{array}$ \\
\hline activity & & & $\%)$ & & & & & & \\
\hline \multirow[t]{8}{*}{ level } & $1-3 \mathrm{hr} /$ week & 59 & $(27$ & 17 & $(24 \%)$ & 14 & $(30$ & 23 & $(24$ \\
\hline & & & $\%)$ & & & & $\%)$ & & $\%)$ \\
\hline & 2-6hr/week & 54 & $(25$ & 20 & $(28 \%)$ & 9 & $(20$ & 31 & $(33$ \\
\hline & & & $\%)$ & & & & $\%)$ & & $\%)$ \\
\hline & $5-9 \mathrm{hr} /$ week & 38 & $(18$ & 12 & $(17 \%)$ & 12 & $(26$ & 11 & $(12$ \\
\hline & & & $\%)$ & & & & $\%)$ & & $\%)$ \\
\hline & $>10 \mathrm{hr} /$ week & 44 & $(20$ & 21 & $(30 \%)$ & 11 & $(24$ & 16 & $(17$ \\
\hline & 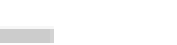 & & $\%)$ & & & & $\%)$ & & $\%)$ \\
\hline
\end{tabular}

This article is protected by copyright. All rights reserved. 


\section{Discussion:}

Overall, there were no significant differences in the incidences of fractures among different groups after adjusting for age, pubertal status, BMI scale, exposure to household smoking, history of bone health supplement use, dietary calcium intake, family history of osteoporosis and physical activity levels. Even though there were significant differences between children with asthma and healthy controls in gender and activity levels, these were not found to be significant in affecting a fracture risk. A number of studies have examined the influence of ICS on BMD in asthmatic children but there was a great disparity in their outcomes. ${ }^{7,11}$ Kelly et al. ${ }^{8}$ reported ICS to be associated with BMD and final adult height but did mention that ICS use can reduce the need for oral corticosteroid therapy which has a greater influence on BMD. Schlienger et $a l .{ }^{13}$ conducted a population-based nested casecontrol study and Van Staa et $a l .^{14}$, conducted a population-based cohort study to investigate fracture risk in children using ICS in the United Kingdom. Schlienger et al. ${ }^{13}$ concluded that ICS use was not associated with a higher risk of fracture incidence. On the contrary, Van Staa et al. ${ }^{14}$. concluded that the use of ICS in asthmatic children was associated with a $15 \%$ increased risk in fractures. Unlike this study, all above mentioned studies did not include any information regarding smoking status, environmental smoke exposure and activity levels, limiting their ability to control for those confounders in their analyses. In a retrospective cohort study with 40-year follow up Melton et al. ${ }^{12}$ investigated fracture risk in asthmatic children without accounting for ICS use. This study indicated that there was no increase in overall fracture risk in children; however, due to the long follow up, these fractures cannot be directly linked to ICS use.

This study did also show that bone health parameters such as adequate calcium and vitamin D supplementation was extremely low ( $<10 \%$ in each sub-group) across the whole study population even though the majority of participants were taking less than the daily recommended calcium intake. Although BMD measurements were out of the scope of this study, hopefully this study still raises awareness that there is room for just the simple recommendation of increasing the uptake of calcium and vitamin D supplementation in paediatrics to improve bone health as a first point of call.

The dental department at the $\mathrm{RCH}$, where the control participants were recruited, is attended by children from lower socioeconomic regions; socio-demographic status has been linked to fracture risk $^{21}$; this may have increased the fracture rate in our healthy control population but due to the anonymous nature of our survey, it is not possible to know to what extent socioeconomic status affected our population. 
Although this study used a questionnaire to collect data increasing the risk of recall bias, the vast majority of the questionnaires were filled out either by one of the parents/guardian or by the child with the parent/guardian alongside them and it is unlikely a child's fracture would have been forgotten. Questionnaires were researcher administered to reduce the likelihood of misinterpretation of questions and missing data. Due to the design of the survey, a great variety of information regarding possible risk factors such as BMI, daily calcium intake, history of bone health supplement use, smoking and exposure to household smoking, activity levels and in-depth information regarding asthma history and asthma control was able to be captured for each study participant. This enabled us to perform extensive analysis on the association between ICS use in asthmatic patients and fracture risk factors. This was particularly useful here as recent studies have shown BMI to be associated both with the severity of asthma symptoms, ${ }^{22}$ as well as an increased risk of fractures in general. ${ }^{23}$

Further research should be performed to investigate prospective, long-term follow up into adult life in conjunction with assessment of ICS adherence and persistence using objective measures and assessment of inhaler techniques. It is important that the impact of ICS on bone health in asthmatic children be extensively examined since fractures can cause severe disability and reduce quality of

life. $^{24-25}$ With the use of techniques like peripheral quantitative computed tomography (pQCT), early changes in bone metabolism and corticosteroid-induced osteoporosis may be monitored and earlier intervention could be implemented to improve bone health in asthmatic children, if warranted.

\section{Acknowledgements:}

The study team would like to thank all the participants for volunteering their time and all the respiratory and general medicine clinicians for their referrals and efforts in assisting recruitment.

\section{References:}

1. Australian Bureau of Statistics. Australian Health survey first results, 2011-2012 'Who gets asthma?'. In: 2011-2012. Canberra, Australia: Australian Institute of Health and Welfare; 2016.

2. Global initiative for asthma (GINA). Global Burden of Asthma. [Internet] 2015 [cited 01/06/2016]; Available from: www.ginaasthma.org 
3. National Asthma Counsil Australia. Australian Asthma Handbook, a quick reference guide. Melbourne, Australia; 2014.

4. Lai CK, Beasley R, Crane J, et al. Global variation in the prevalence and severity of asthma symptoms: phase three of the International Study of Asthma and Allergies in Childhood (ISAAC). Thorax 2009;64(6):476-483.

5. Kappelman MD, Galanko JA, Porter CQ, Sandler RS. Risk of diagnosed fractures in children with inflammatory bowel diseases. Inflamm Bowel Dis 2011;17(5):1125-1130.

6. Rousseau-Nepton I, Lang B, Rodd C. Long-term bone health in glucocorticoid-treated children with rheumatic diseases. Curr Rheumatol Rep 2013;15(3):315.

7. Fuhlbrigge AL, Kelly HW. Inhaled corticosteroids in children: effects on bone mineral density and growth. Lancet Respir Med 2014;2(6):487-496.

8. Kelly HW, Van Natta ML, Covar RA, et al. Effect of long-term corticosteroid use on bone mineral density in children: a prospective longitudinal assessment in the childhood Asthma Management Program (CAMP) study. Pediatrics 2008;122(1):e53-61.

9. Cooper C, Dennison EM, Leufkens HG, Bishop N, van Staa TP. Epidemiology of childhood fractures in Britain: a study using the general practice research database. $J$ Bone Miner Res 2004;19(12):1976-1981.

10. Vestergaard P, Rejnmark L, Mosekilde L. Fracture risk in patients with chronic lung diseases treated with bronchodilator drugs and inhaled and oral corticosteroids. Chest 2007;132(5):1599-1607.

11. Mortimer KJ, Harrison TW, Tattersfield AE. Effects of inhaled corticosteroids on bone. Ann Allergy Asthma Immunol 2005;94(1):15-21; quiz 22-13, 79.

12. Melton LJ, 3rd, Patel A, Achenbach SJ, Oberg AL, Yunginger JW. Long-term fracture risk among children with asthma: a population-based study. $J$ Bone Miner Res 2005;20(4):564-570.

13. Schlienger RG, Jick SS, Meier CR. Inhaled corticosteroids and the Risk of Fractures in Children and Adolescents. Pediatrics 2004;114(2):469-473. 
14. Van Staa TP, Bishop N, Leufkens HG, Cooper C. Are inhaled corticosteroids associated with an increased risk of fracture in children? Osteoporos Int 2004;15(10):785-79110.

15. Philip J. The Effects of Inhaled Corticosteroids on Growth in Children. Open Respir Med J 2014;8:66-73.

16. Teitelbaum SL. Glucocorticoids and the osteoclast. Clin Exp Rheumatol 2015;33(4 Suppl 92):S37-39.

17. = Lems WF. Glucocorticoids: bad or safe for the bones? RMD Open 2015;1(Suppl 1):e000050.

18 Loke YK, Gilbert D, Thavarajah M, Blanco P, Wilson AM. Bone mineral density and fracture risk with long-term use of inhaled corticosteroids in patients with asthma: systematic review and meta-analysis. BMJ Open 2015;5(11):e008554.

19. The Childhood Asthma Management Program Research Group. Long-term effects of budesonide or nedocromil in children with asthma. N Engl J Med 2000;343(15):1052 - 1063.

20. Juniper EF, O'Byrne PM, Guyatt GH, Ferrie PJ, King DR. Development and validation of a questionnaire to measure asthma control. Eur Respir J 1999;14:902-907.

21. Ramaesh R, Clement ND, Rennie L, Court-Brown C, Gaston MS. Social deprivation as a risk factor for fractures in childhood. Bone Joint J 2015;97-B(2):240-245.

22. Corbo GM, Forastiere F, De Sario M et al. Wheeze and asthma in children: associations with body mass index, sports, television viewing, and diet. Epidemiology 2008;19(5):747-755.

23. Auer RT, Mazzone P, Robinson L, Nyland J, Chan G. Childhood Obesity Increases the Risk of Failure in the Treatment of Distal Forearm Fractures. J Pediatr Orthop 2015.

24. Ding R, McCarthy ML, Houseknecht E et al. The health-related quality of life of children with an extremity fracture: a one-year follow-up study. J Pediatr Orthop 2006;26(2):157-163.

25. Stancin T, Kaugars AS, Thompson GH et al. Child and family functioning 6 and 12 months after a serious pediatric fracture. J Trauma 2001;51(1):69-7626. 


\section{University Library}

\section{- M M N E R VA A gateway to Melbourne's research publications}

Minerva Access is the Institutional Repository of The University of Melbourne

Author/s:

Zieck, SE;George, J;Blakeley, BA;Welsh, L;James, S;Ranganathan, S;Simm, P;Lim, A

Title:

Asthma, bones and corticosteroids: Are inhaled corticosteroids associated with fractures in children with asthma?

Date:

2017-08-01

\section{Citation:}

Zieck, S. E., George, J., Blakeley, B. A., Welsh, L., James, S., Ranganathan, S., Simm, P. \& Lim, A. (2017). Asthma, bones and corticosteroids: Are inhaled corticosteroids associated with fractures in children with asthma?. JOURNAL OF PAEDIATRICS AND CHILD HEALTH, 53 (8), pp.771-777. https://doi.org/10.1111/jpc.13554.

Persistent Link:

http://hdl.handle.net/11343/292990 